\title{
Synergistic effect of honey and Nigella sativa on wound healing in rats ${ }^{1}$
}

Seyed Mohammad Reza Javadi', Mamak Hashemi", Younes Mohammadi"', Alireza MamMohammadi" Ali Sharifiv, Hamid Reza Makarchian ${ }^{\mathrm{VI}}$

'Assistant Professor, Fellow of Surgery, Department of Surgery, Hamadan University of Medical Sciences, Iran. Scientific, intellectual, conception and design of the study; critical revision.

"Associate Professor, Department of Iranian Traditional Medicine, School of Medicine, Hamadan University of Medical Sciences, Iran. Technical procedures, manuscript writing.

"'Assistant Professor, Department of Epidemiology, School of Public Health, Hamadan University of Medical Sciences, Iran. Statistical analysis, manuscript preparation.

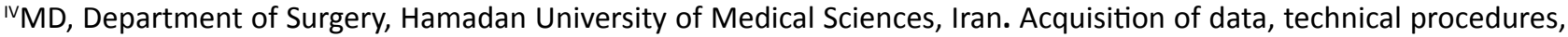
manuscript preparation.

${ }^{v}$ Assistant Professor, Fellow of Surgery, Department of Surgery, Hamadan University of Medical Sciences, Iran. Analysis and interpretation of data, critical revision.

V'Assistant Professor, Fellow of Surgery, Department of Surgery, Hamadan University of Medical Sciences, Iran. Conception and design of the study, final approval.

\section{Abstract}

Purpose: To investigate the therapeutic potential of honey, Nigella sativa (N. sativa) and their combination in rat model of excisional wound healing.

Methods: A circular excision wound was established in the back region of 50 Wistar rats. Subsequently, they were divided into 5 groups and daily topical administration of lanolin in the control group, honey in the honey group, cold-pressed N. sativa seed oil in the N. sativa groups, mix of 1:1 ratio of honey and $\mathrm{N}$. sativa seed oil in the mix group, and phenytoin cream in the phenytoin group were used. Then, wound surface areas were evaluated using digital camera immediately after the injury and at post excision days 5, 10, 15 and 20.

Results: Significant reduction in wound surface area was observed within and between the groups $(P<0.001)$. In the post excision days 5, 10, 15 and 20 the wound surface areas in the mix group were significantly lower than the other groups followed by the phenytoin, honey, N. sativa, and control groups.

Conclusion: The wound healing may be improved and accelerated by using topical solutions of honey, N. sativa seed oil and especially their mixture.

Key words: Honey. Nigella sativa. Wound healing. Rats. 


\section{Introduction}

Cutaneous wound healing is a significant concern in many pathologies induced by surgery, trauma, and burn ${ }^{1,2}$. The process of cutaneous wound healing involves diverse phases of hemostasis, inflammation, proliferation and remodeling including a regulated cascade of bio-molecular events for regeneration and restoration ${ }^{2}$. There are several studies addressing the factors that influence the wound healing process to find therapeutics that will improve wound healing however, much remains to be learned. Nowadays, the trend for using natural products for wound healing is growing worldwide ${ }^{3}$.

Honey comprising wide range of flavonoids, phenolic acid, organic acids, enzymes and vitamins may improve wound healing ${ }^{4}$. Collagen formation and fibroblast deposition can also be facilitated by the large amount of amino acids found in honey ${ }^{5,6}$. Besides, antibacterial and anti-inflammatory properties of honey prevents delay in wound healing process ${ }^{7}$. Nigella sativa (N. sativa), an annual flowering plant native to the South and Southeast Asia has been found to have antioxidative, anti-inflammatory, antibacterial and wound healing properties ${ }^{8-12}$. However, toxicity has been reported with chronic and large surface area use of N. sativa ${ }^{13,14}$. Thus, combination of the two substances may serve as an alternative approach to reduce possible side effects.

In the present study we are aiming to evaluate the effectiveness of honey, $\mathrm{N}$. sativa seed oil and their combination in an experimental rat model of cutaneous wound healing.

\section{Methods}

This study was conducted after approval of the Animal Ethics Committee of Hamadan University of Medical Sciences, Iran. All required procedures were performed on animals after induction of general anesthesia.
All efforts were made to minimize animals' suffering during the experiment.

Fifty male albinos Wistar rats were studied with weight range of 200-220 grams. Rats were kept in separate clean cages. All animals were acclimated for 1 week before experiment under the temperature controlled $\left(22^{\circ} \mathrm{C} \pm 2^{\circ} \mathrm{C}\right)$ and humidity controlled $(60 \%$ $\pm 5 \%$ ) environment and 12 hour light/dark photocycles. Rat pellet and water were accessible ad libitum.

The rats were randomly divided into 5 groups, with 10 rats in each including control, honey, N. sativa, mix, and phenytoin groups. All were anesthetized with intraperitoneal xylazine $10 \mathrm{mg} / \mathrm{kg}$ and ketamine $80 \mathrm{mg} / \mathrm{kg}$. After that, the skin was shaved using an electrical shaver and disinfected with $70 \%$ alcohol. A circular excision wound $2 \mathrm{~cm}$ in diameter was established in the back region of all rats with a surgical scalpel by a same surgeon. Subsequently, daily topical administration of 2 grams of lanolin (Darou Pakhsh Pharma Chem Co., Tehran, Iran) in the control group, honey obtained from west Alborz mountain region, Iran in the honey group, cold-pressed N. sativa seed oil (Barij Essence Company; Kashan, Iran) in the N. sativa groups, mix of 1:1 ratio of honey and $\mathrm{N}$. sativa seed oil in the mix group, and phenytoin cream 1\% (Darou Pakhsh Pharma Chem Co., Tehran, Iran) in the phenytoin group as a positive control group were used.

The honey was collected from the nectar of local plants in late spring from the mountainous region. For isolation of impurities, honey was filtered with $0.5 \mathrm{~mm}$ Whatman filter at $25-30^{\circ} \mathrm{C}$ temperature. The high temperature was not used in any way because the high heat causes loss of beneficial compounds of honey such as proline amino acid. The analysis of honey revealed $14.4 \%$ moisture, $68.91 \%$ reducing sugar, $1.82 \%$ sucrose, $\mathrm{pH} 3.81$, fructose/glucose ratio 0.9 , $0.03 \%$ Ash content, free acidity $15.2 \mathrm{mEq} / \mathrm{kg}$ and hydroxymethylfurfural $11.52 \mathrm{ppm}$. 
The wound healing process in all animals was photographically observed at excision day (day 0 ) and post excision days $5,10,15$, and 20 using images taken from skin wounds using a Panasonic LUMIX digital camera (LUMIX FZ1000 4K QFHD/HD 16X). The camera was fixed at a distance of $10 \mathrm{~cm}$ from the wound surface (vertical view) to calibrate the magnification of the photographs. In addition, a same fine-line ruler was kept at wound level at the time of imaging. Calculation of the wound area was performed by Digimizer 4.6.1 (MedCalc Software, Belgium, 2016) image analysis software.

\section{Statistical analysis}

Statistical analysis was performed by using SPSS software (version 19.0, SPSS Inc., Chicago, Illinois). Data were compared using one-way ANOVA test. A $P$ value less than 0.05 was considered statistically significant.
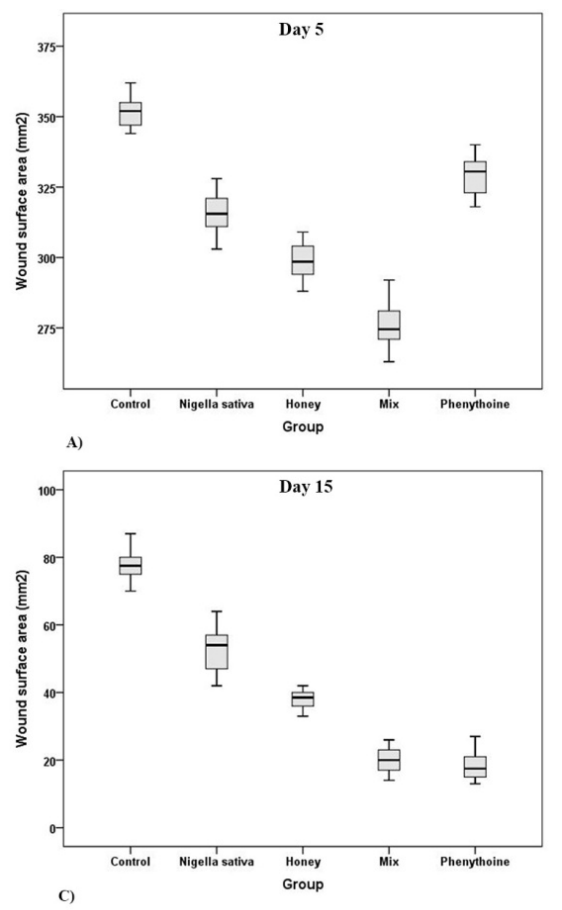

\section{Results}

Expectedly, in the day 0, the wound surface area was not significantly different between the five groups $\left(416.2 \pm 7.4 \mathrm{~mm}^{2}, 411\right.$ $\pm 7.8 \mathrm{~mm}^{2}, 417 \pm 8.9 \mathrm{~mm}^{2}, 414 \pm 7.2 \mathrm{~mm}^{2}$, and $421 \pm 10.4 \mathrm{~mm}^{2}$ in the control, N. sativa, honey, mix, and phenytoin groups, respectively). The measurements of wound surface area in the following post excision days in each group and their associations are shown in Figure 1. Interestingly, in the post excision days 5, 10, 15 and 20 the wound surface areas in the mix group were significantly lower than the other groups followed by the phenytoin, honey, $\mathrm{N}$. sativa, and control groups except for the post excision days 15 and 20 in which the wound surface area of the phenytoin group was lower than the mix group however, the latter difference was not significant. The trend of reduction of wound surface area in the post excision days in each group are shown in Figure 2.
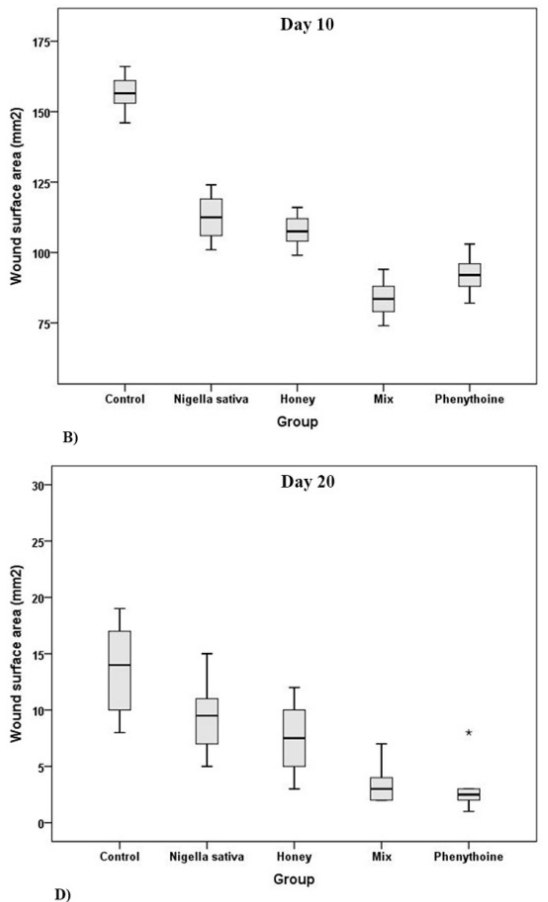

Figure 1 - A) The wound surface area in day $5(p<0.001)$. B) The wound surface area in day $10(p<0.001$, except for the Nigella sativa vs. honey and mix vs. phenytoin group with $p$ values 0.62 and 0.05 , respectively). C) The wound surface area in day 15 ( $p<0.001$, except for the mix vs. phenytoin group with $p$ value 0.92.). D) The wound surface area in day 20 ( $p<0.001$, except for the control vs. Nigella sativa, Nigella sativa vs. honey, honey vs. mix, and mix vs. phenytoin group with $\mathrm{p}$ values $0.14, .63,0.03$, and 0.98 , respectively). 


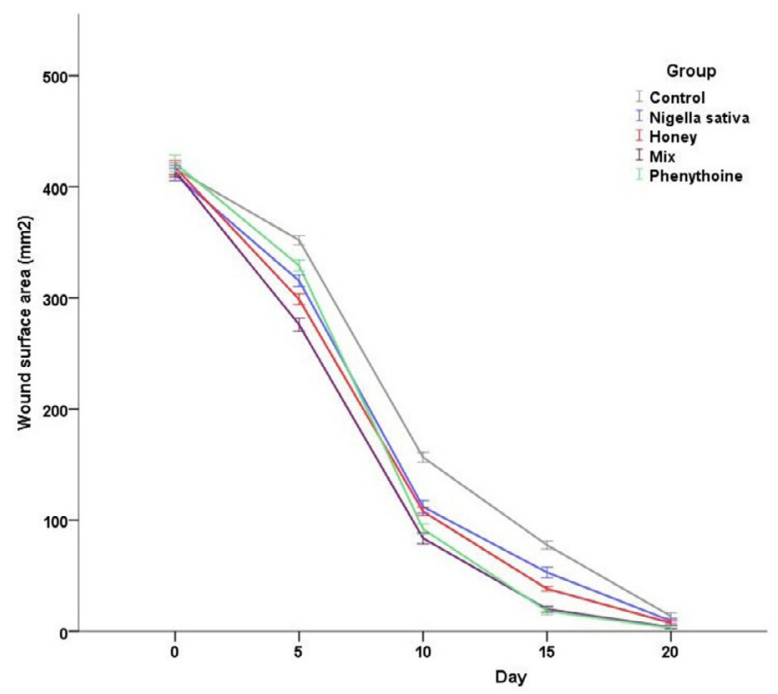

Figure $\mathbf{2}$ - The trend of reduction of wound surface area through the post excision days in each group.

\section{- Discussion}

Topical administration of honey in our experimental study associated with significant reduction of wound surface area compared to the control group in the all 20 post excision days and compared to the phenytoin group in the first 5 post excision days. Positive impact of honey wound dressing has been shown by previous studies ${ }^{15-17}$. Low $\mathrm{pH}$, hydrogen peroxide, anti-inflammatory, antioxidant and antimicrobial properties of honey are believed to be the contributing factors for the beneficial effect of honey in wound healing. Additionally, absorption of excessive wound exudate is possible due to hyperosmotic and hygroscopic capacity that causes weight gain under physiological condition ${ }^{5-7}$.

Our investigation revealed that using cold pressed N. sativa seed oil was also associated with significant reduction of wound surface area compared to the control group in the 15 post excision days and compared to the phenytoin group in the first 5 post excision days. In a study by Yaman et al. ${ }^{18}$, using $\mathrm{N}$. sativa in a rat model of burn wound injury was associated with improved wound healing with no macroscopic or microscopic signs of infection. In another experimental study by Sarkhail et al. ${ }^{19}$ by applying hexanic extract of $N$. sativa seed on burn wound, the district of wound significantly decreased compare to the control group after 12 days. The antibacterial and immunomodulating effect of petroleum ether extract of $\mathrm{N}$. sativa seeds was investigated by Abu-Al-Basal et al. ${ }^{20}$ in mice. In their study they showed that the healing process improved by decreasing the total and absolute white blood cells count, reducing tissue damage and decreasing bacterial expansion. Thymoquinone a major component of $\mathrm{N}$. sativa seeds, is thought to be the responsible active molecule for the antiinflammatory, antioxidant and antibacterial properties of $\mathrm{N}$. sativa which may lead to positive impact on wound healing ${ }^{21}$.

In the honey and N.sativa seed oil yielded similar results on day 10 and 20, nevertheless, both groups were significantly weaker than phenytoin treatment. Analogous efficacy is suggested by the results.

In our study, the mixture of honey and N. sativa seed oil exhibited the best significant outcome compared to the control, honey or $\mathrm{N}$. sativa groups in the all post excision days. Comparing to the phenytoin group, the mix group showed better early outcome in the post excision day 5 however, in the following days, the wound surface areas in the two groups were not significantly different.

\section{- Conclusion}

The wound healing may be improved and accelerated by using honey, N. sativa seed oil and especially their mixture. 


\section{References}

1. Bayat A, McGrouther DA, Ferguson MW. Skin scarring. Bmj. 2003 Jan 11;326(7380):88-92. PMID: 12521975.

2. Strecker-McGraw MK, Jones TR, Baer DG. Soft tissue wounds and principles of healing. Emerg Med Clin North Am. 2007 Feb;25(1):1-22. PMID: 17400070.

3. Maver T, Maver U, Stana Kleinschek K, Smrke DM, Kreft S. A review of herbal medicines in wound healing. Int J Dermatol. 2015 Jul;54(7):740-51. PMID: 25808157.

4. Wang J, Li QX. Chemical composition, characterization, and differentiation of honey botanical and geographical origins. Adv Food Nutr Res. 2011;62:89-137. PMID: 21504822.

5. Saikaly SK, Khachemoune A. Honey and wound healing: an update. Am J Clin Dermatol. 2017 Apr;18(2):237-51. PMID: 28063093.

6. Tan MK, Hasan Adli DS, Tumiran MA, Abdulla MA, Yusoff KM. The Efficacy of gelam honey dressing towards excisional wound healing. Evid Based Complement Alternat Med. 2012;2012:805932. doi: 10.1155/2012/805932.

7. Vallianou N, Gounari P, Skourtis A, Panagos J, Kazazis C. Honey and its anti-inflammatory, anti-bacterial and anti-oxidant properties. Gen Med (Los Angel). 2014;2(132):1-5.

8. Zohary D, Hopf M, Weiss E. Domestication of plants in the old world: the origin and spread of domesticated plants in Southwest Asia, Europe, and the Mediterranean Basin: OUP Oxford; 2012.

9. Emeka LB, Emeka PM, Khan TM.Antimicrobial activity of Nigella sativa L. seed oil against multi-drug resistant Staphylococcus aureus isolated from diabetic wounds. Pak J Pharm Sci. 2015 Nov;28(6):1985-90. PMID: 26639493.

10.Awadalla EA. Ameliorative effect of the crude oil of the Nigella sativa on oxidative stress induced in rat testes by cisplatin treatment. Biomed Prevent Nutr. 2012;2(4):265-8.

11. Mohammed NK, Abd Manap MY, Tan CP, Muhialdin BJ, Alhelli AM, Meor Hussin AS. The effects of different extraction methods on antioxidant properties, chemical composition, and thermal behavior of black seed (Nigella sativa L.) oil. Evid Based Complement Alternat Med. 2016;2016:6273817. doi: $10.1155 / 2016 / 6273817$.

12. Majdalawieh AF, Fayyad MW. Immunomodulatory and antiinflammatory action of Nigella sativa and thymoquinone: A comprehensive review. Int Immunopharmacol. 2015 Sep;28(1):295304. PMID: 26117430.

13.Zaghlol DAA, Kamel ES, Mohammed DS, Abbas NH. The possible toxic effect of different doses of Nigella sativa oil on the histological structure of the liver and renal cortex of adult male albino rats. Egyptian J Histol. 2012;35(1):127-36.

14.Zaoui A, Cherrah Y, Mahassini N, Alaoui $\mathrm{K}$, Amarouch $\mathrm{H}$, Hassar $\mathrm{M}$. Acute and chronic toxicity of Nigella sativa fixed oil. Phytomedicine. 2002 Jan;9(1):69-74. PMID: 11924767.

15.Chamani G, Zarei MR, Mehrabani M, Mehdavinezhad A, Vahabian M, AhmadiMotamayel F. Evaluation of honey as a topical therapy for intraoral wound healing in rats. Wounds. 2017 Mar;29(3):80-6. PMID: 28054920.

16.Takzaree N, Hadjiakhondi A, Hassanzadeh $G$, Rouini MR, Manayi A. Synergistic effect of honey and propolis on cutaneous wound healing in rats. Acta Med Iran. 2016 Apr;54(4):233-9. PMID: 27309263.

17. Takzaree N, Hassanzadeh G, Rouini MR, Manayi A, Hadjiakhondi A, Majidi Zolbin M. Evaluation of the effects of local application of thyme honey in open cutaneous wound healing. Iran J Public Health. 2017 Apr;46(4):545-51. PMID: 28540272.

18.Yaman I, Durmus A, Ceribasi S, Yaman M. Effects of Nigella sativa and silver sulfadiazine on burn wound healing in rats. Vet Med (Praha). 2010;55(12):619-24.

19.Sarkhail P, Esmaily H, Baghaei A, Shafiee A, Abdollahi M, Khademi Y, Madandar M, Sarkheil P. Burn healing potential of Nigella sativa seed oil in rats. Int J Pharm Sci Res. 2011;2(1):34-40.

20.Abu-Al-Basal MA. Influence of Nigella sativa fixed oil on some blood parameters and histopathology of skin in staphylococcalinfected BALB/c mice. Pak J Biol Sci. 2011 
Dec 1;14(23):1038-46. PMID: 22590837.

21.Khader M, Eckl PM. Thymoquinone: an emerging natural drug with a wide range of medical applications. Iran J Basic Med Sci. 2014 Dec;17(12):950-7. PMID: 25859298.

\section{Correspondence:}

Seyed Mohammad Reza Javadi Shahid Beheshti Boulevard, Besat Hospital, General Surgery Department Hamadan Iran Phone: +988132640020 smrezajavadi@gmail.com

Received: Feb 09, 2018

Review: Apr 13, 2018

Accepted: May 12, 2018
Conflict of interest: none

Financial source: none

$(\mathrm{cc}) \mathrm{BY}$ 